\title{
The Development of Predictive Growth Models for Total Viable Cells and Escherichia coli on Chicken Breast as a Function of Temperature
}

\author{
Chan $\mathrm{Heo}^{1}$, Ji Hyun Kim¹, Hyoun Wook Kim², Joo-Yeon Lee², Wan-Soo Hong ${ }^{3}$, \\ Cheon-Jei Kim ${ }^{1}$, and Hyun-Dong Paik ${ }^{1} *$ \\ ${ }^{1}$ Division of Animal Life Science, Konkuk University, Seoul 143-701, Korea \\ ${ }^{2}$ Korea Livestock Products HACCP Management Institute, Anyang 430-731, Korea \\ ${ }^{3}$ Department of Foodservice Management and Nutrition, Sangmyung University, Seoul 110-743, Korea
}

\begin{abstract}
The aim of this research was to estimate the effect of temperature and develop predictive models for the growth of total viable cells (TVC) and Escherichia coli (EC) on chicken breast under aerobic and various temperature conditions. The primary models were determined by Baranyi model. The secondary models for the specific growth rate (SGR) and lag time (LT), as a function of storage temperature, were developed by the polynomial model. The initial contamination level of chicken breasts was around 4.3 Log CFU/g of TVC and 1.0 Log CFU/g of E. coli. During $216 \mathrm{~h}$ of storage, SGR of TVC showed $0.05,0.15$, and $0.54 \mathrm{Log} \mathrm{CFU} / \mathrm{g} / \mathrm{h}$ at 5,15 , and $25^{\circ} \mathrm{C}$. Also, the growth tendency of EC was similar to those of TVC. As storage temperature increased, the values of SGR of microorganisms increased dramatically and the values of LT decreased inversely. The predicted growth models with experimental data were evaluated by $B_{f}, A_{f}, R M S E$, and $R^{2}$. These values indicated that these developed models were reliable to express the growth of TVC and EC on chicken breasts. The temperature changes of distribution and showcase in markets might affect the growth of microorganisms and spoilage of chicken breast mainly.
\end{abstract}

Key words: chicken breast, predictive modeling, Baranyi model, polynomial model, temperature abuse

\section{Introduction}

In Korea, for the improvement of the slaughtering sanitation, the government announced officially that every slaughterhouse must pass the HACCP (Hazard Analysis Critical Control Point) qualification that is specially designed for minimizing food safety risks from July 1 , 2003 (MIFAFF, Notification No. 1999-29). Now it is well accepted that it is the responsibility of industries to produce, transport, process, and package foods that have a minimum level of microbiological, chemical risk from food borne disease (Michael and Beuchat, 2007). Therefore, more researches are necessary to support the system development and guide the microbiological risk assessment (Oh and Lee, 2001; Cha et al., 2004).

In recent years, consumer demand has increased for foods that are highly qualified and safer. However, it was reported that the illness associated with pathogen in food,

*Corresponding author : Hyun-Dong Paik, Division of Animal Life Science, Konkuk University, Seoul 143-701, Korea. Tel: 822-2049-6011, Fax: 82-2-455-3082, E-mail: hdpaik@konkuk.ac.k such as Salmonellosis, happened approximately 40,000 cases in the United States annually (CDC, 2005). Also, it was reported that these kinds of disease can be caused by temperature abuse during storage and distribution, and the cross-contamination like slaughter processing (Juneja et al., 2007). Therefore, the predictive modeling, as an important tool, has been introduced to predict behavior of microorganisms under the influence of environmental factors such as temperature, $\mathrm{pH}$, and $\mathrm{a}_{\mathrm{w}}$ (Zurera-Cosano et al., 2006).

The application of predictive models allows to quantify and to predict the rate of microbial growth under controlled conditions with the intention of assuring the hygienic quality of food. For example, specific spoilage microorganisms such as Pseudomonas spp. in poultry under variable temperature conditions were selected and the growth models were developed (Gospavic et al., 2008). Juneja et al. (2007) developed the predictive models for Salmonella serotypes cocktail in vacuum sealed minced chicken tenderloins under various temperature conditions. However, depending on minced or not, the growth of microorganisms on meat products can be dif- 
ferent clearly. Packaging conditions like vacuum sealed or aerobic storage can be another factor to influence the microbial growth. Until now, many research literatures were focused on the growth of a single strain of pathogenic bacteria or developing the models under broth condition.

Therefore, the objective of this study was to model the effects of various temperature conditions for the growth of natural microorganisms (total viable cells and Escherichia coli) on raw chicken meat (not minced) during aerobic storage. These models can show the reliable quantitative levels of microorganisms on chicken products for improvement of microbiological quality assurance.

\section{Materials and Methods}

\section{Preparation of chicken breasts}

Chicken breasts were purchased from local processors in Seoul, Korea within $12 \mathrm{~h}$ after slaughtering. Purchased chicken breasts in $30 \times 19 \mathrm{~cm}$ polyethylene bag with a cooling box $\left(<5^{\circ} \mathrm{C}\right)$ and delivered to the laboratory within $1 \mathrm{~h}$. In the laboratory, all subcutaneous and inter-muscular fat and visible connective tissue were removed from individual chicken breasts under aseptic conditions. Samples $(300 \pm 10 \mathrm{~g}$, three loaf of chicken breast) were put in individual polyethylene bags and not sealed for maintaining aerobic condition. All polyethylene bags with samples were divided into three parts and were stored under constantly controlled temperature conditions in incubators (Eyela LTI-700, Rikakikai Co., Ltd., Tokyo, Japan) at 5, 15 , and $25^{\circ} \mathrm{C}$.

\section{Microbiological analysis}

For bacterial counts on chicken breasts, bacteriological analytical manual was used (BAM, 2003). For each sampling, $10 \mathrm{~g}$ of chicken breast was aseptically transferred into a sterile stomacher bag at each respective sampling interval and $100 \mathrm{~mL}$ of sterile $0.1 \%$ peptone water was added. The sample was then evenly mixed in the stomacher (Masticator-Paddle-Blender, IUL Instrument, Spain) for $2 \mathrm{~min}$ at normal speed and aliquots were plated out directly or as 10 -fold dilutions in $0.1 \%$ peptone water. After serially diluting each sample in sterile peptone water, $0.1 \mathrm{~mL}$ portions of the samples were separately plated onto each of plates. Total viable cell (TVC) was enumerated by incubation on Plate Count Agar (PCA; Difco, USA) at $35^{\circ} \mathrm{C}$ for $48 \mathrm{~h}$. The number of $E$. coli (EC) was estimated by incubation on Petrifilm ${ }^{\mathrm{TM}}$ (E. coli/ Coliform count plate, 3M Microbiology Products, USA) at $35^{\circ} \mathrm{C}$ for $48 \mathrm{~h}$. We enumerated blue to red-blue colonies associated with entrapped gas, regardless of size or intensity of color, as conformed EC. But blue colonies without gas are not counted as EC. After incubation such plates, which contained 30 to 300 colonies on a plate, were chosen for counting. All analyses were performed three times and counts were expressed as colony-forming units per gram $(\mathrm{CFU} / \mathrm{g})$. During the experiments, all samples were stored aerobically under controlled temperatures $\left(5,15\right.$, and $\left.25^{\circ} \mathrm{C}\right)$ in incubators. Every measurement was repeated at least 3 times.

\section{Primary modeling of microorganisms}

The growth curves of TVC and EC were developed by using re-parameterized Baranyi model equation (Baranyi and Roberts, 1994). The re-parameterized model is described by form Eq. (1), (2), and (3).

$$
\begin{aligned}
& y(t)=y_{0}+\frac{y_{1}}{\ln (10)}-\frac{y_{2}}{\ln (10)} \\
& y_{1}=\mu \cdot t+\ln \left\lfloor e^{-\mu \cdot t}-e^{-\mu\left(t+t_{\text {lag }}\right)}+e^{-\mu \cdot t_{\text {lag }}}\right\rfloor \\
& y_{2}=\ln \left\lfloor 1+10^{\left(y_{0}-y_{\max }\right)} \cdot\left(e^{\mu\left(t+t_{\text {lag }}\right)}-e^{\left.-\mu \cdot t_{\text {lag }}\right)}\right\rfloor\right.
\end{aligned}
$$

Where $y(t)$ is the bacterial count in Log CFU/g at time $t ; y_{0}$ is the initial bacteria count in Log CFU/g at time 0; $y_{\max }$ is the maximum bacteria count in Log CFU/g; $t_{\text {lag }}$ means lag time (LT); $\mu_{\max }$ is the maximum specific growth rate (SGR), $\log \mathrm{CFU} / \mathrm{g} / \mathrm{h}$. The average parameters of $y_{0}$, $y_{\max }, \mathrm{LT}, \mu_{\max }$ in this study were determined by using the MicroFit version 1.0 (developed by the Institute of Food Research, Norwich, UK).

\section{Secondary modeling of microorganisms}

To describe the effects of temperature $\left(5,15\right.$, and $\left.25^{\circ} \mathrm{C}\right)$ on growth of TVC and EC on chicken breast, the polynomial model equation was chosen, based on the parameters of primary models. To describe the temperature effect on SGR and LT, the polynomial model equation was described in the following Eq. (4 and 5).

$$
\begin{aligned}
& \mathrm{Ln}(\mathrm{SGR})=a+b \mathrm{~T}+c \mathrm{~T}^{2} \\
& \mathrm{Ln}(\mathrm{LT})=a+b \mathrm{~T}+c \mathrm{~T}^{2}
\end{aligned}
$$

Where $a, b$, and $c$ are constants, $\mathrm{T}$ is temperature $\left({ }^{\circ} \mathrm{C}\right)$. To obtain three constants $(a, b$, and $c)$, all data were fitted using the nonlinear regression procedure, PROC NLIN, with SAS version 9.1 (SAS, 1999). 


\section{Evaluation of predictive models}

Goodness-of-fit of predictive models (primary and secondary models) was evaluated using the coefficient of determination $\left(R^{2}\right)$, bias factor $\left(B_{f}\right)$, accuracy factor $\left(A_{f}\right)$, and root mean square error (RMSE) (Baranyi et al., 1996; Ross et al., 1996).

$$
\begin{aligned}
& B_{f}=10^{\left(\frac{\sum \log \left(\frac{\text { pred }}{\text { obs }}\right)}{n}\right)} \\
& A_{f}=10^{\left(\frac{\sum \log \left(\frac{\text { pred }}{\text { obs }}\right)}{n}\right)} \\
& R M S E_{f}=\sqrt{\frac{\sum(\text { obs-pred })^{2}}{n}}
\end{aligned}
$$

Where obs means observed value; pred means predicted value; $n$ is the number of observations. Perfect agreement between predictions and observations leads to bias and accuracy factors equal to $1.0 . B_{f}$ shows the experimental data lies above or below the predictive data and $A_{f}$ shows the distance between each experimental data and predictive data as a measure how they are close (Seo et al., 2007). A value higher than 1, the values indicate that predicted values are larger than observed values. $R M S E$ is effectively the average difference between the model and the date points. It has the same units as the data (typically Log CFU/g) (Eq. (8)).

\section{Results and Discussion}

\section{Primary and secondary models of microorganisms on chicken breast}

All predictive models were developed by the Baranyi and polynomial model equation (form Eq. (1), (2), (3), (4), and (5)). All plots (experimental data) of microbial counts versus time (h) under each temperature were used to develop the predictive models. Fig. 1(A) and 1(B) show the growth of microorganisms (total viable cells, TVC; E. coli, EC) on aerobically stored chicken breast at 5, 15, and $25^{\circ} \mathrm{C}$, respectively. Also, Fig. 2(A) and 2(B) show the secondary models of the specific growth rate (SGR) and lag time (LT) against temperature $\left(5-25^{\circ} \mathrm{C}\right)$.

The counts of aerobic microorganisms on poultry carcasses after final washing showed around $4 \mathrm{Log}$ CFU/mL and $5 \mathrm{Log} C \mathrm{FU} / \mathrm{mL}$ after evisceration during autumn and winter time (Cha et al., 2004). And the number of TVC and EC on carcasses after washing and cooling were around 3.58 and $0.64 \mathrm{Log} \mathrm{CFU} / \mathrm{cm}^{2}$, respectively (Gill et al., 2006). In our experiments, similar values were
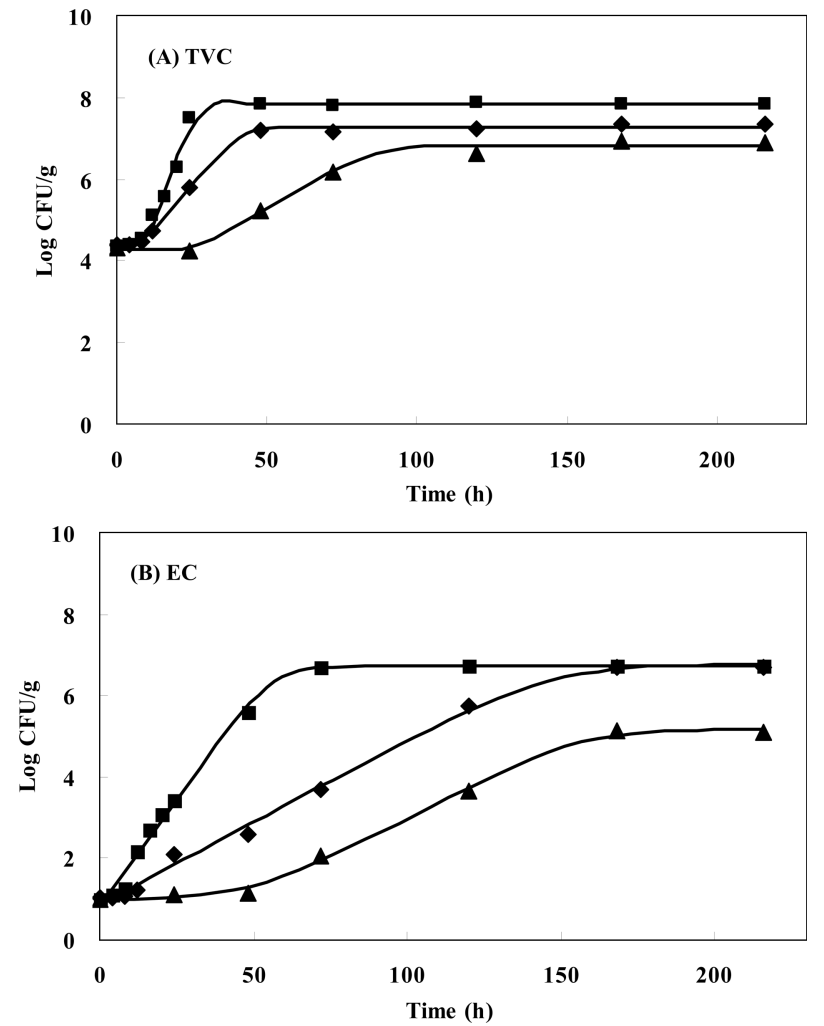

Fig. 1. Primary models of TVC (A) and EC (B) on chicken breasts under different temperature conditions (-, Predictive models; Plots, experimental data $\left(\Delta, 5^{\circ} \mathrm{C}\right.$; $\left.\diamond, 1^{\circ} \mathrm{C} ; \square, 25^{\circ} \mathrm{C}\right)$.

obtained (data not shown). Therefore, Table 2 shows that the predictive initial cell counts of TVC from each sample were around 4.23-4.40 Log CFU/g. And those of EC were 0.88-1.00 Log CFU/g. The initial counts of TVC were significantly not different from each other depending on storage temperature $(p>0.05)$. However, the maximum cell counts showed different tendency depending on storage temperature. The samples which were stored under higher temperature, showed significantly higher values $(p<0.05)$ in maximum cell counts. The values of SGR showed inversely proportional to LT (Table 1 and Fig. 1(A)). Those results mean that the growth of TVC can be influenced dependently by storage temperature. It was reported that temperature is one of important environmental parameters affecting the microbial growth and spoilage in meat or meat products (Thomas and Mathews, 2004). As the storage temperature is decreased, the generation time and LT of TVC are increased, and therefore, the growth is slowed.

The predictive growth model of EC was also developed (Fig. 1(B)). Both SGR and LT were temperature-dependant significantly like those of TVC $(p<0.05)$. Comparing with the growth parameter of TVC (Table 1), the initial, 

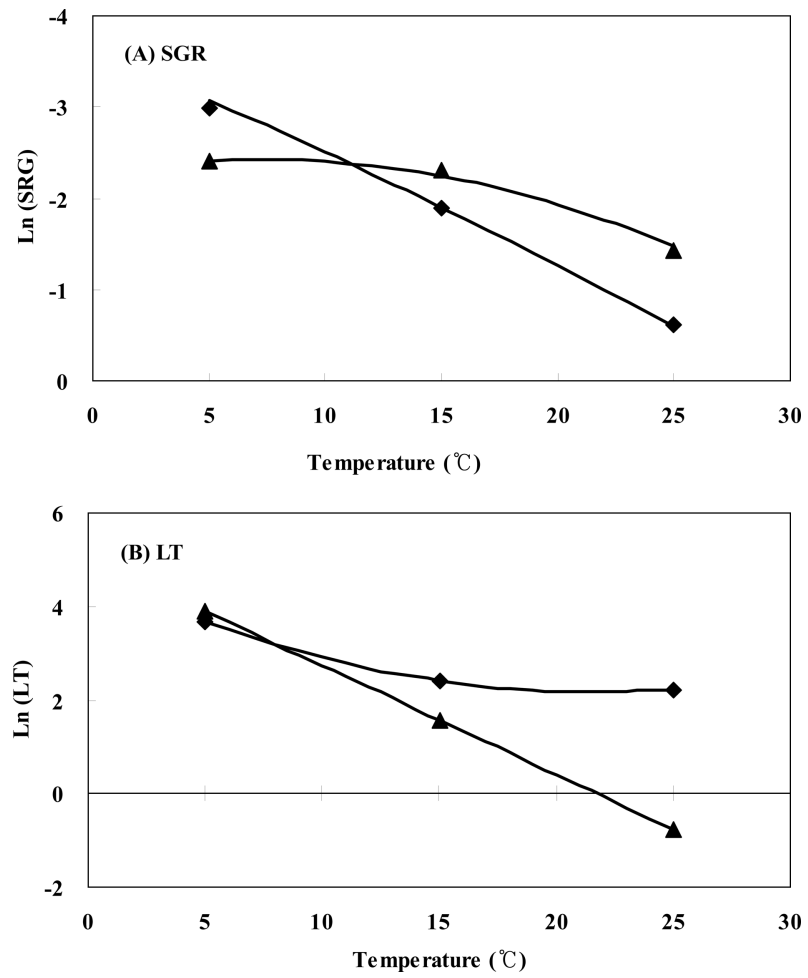

Fig. 2. Secondary models for the effect of temperature on SGR (A) and LT (B) (-, Predictive models; Plots, experimental data $(\diamond$, TVC; $\Delta$, EC) $)$.

maximum counts and values of SGR of EC were lower than those of TVC, respectively. However, increasing the storage temperature, the values of LT were predicted that EC had shorter LT than TVC. There are not enough data to compare with predictive models for natural microorganisms like TVC and EC under real foods. The published information has shown the predictive growth model with artificially contaminated broth condition. For example, Fujikawa and Morozumi developed the growth model of a single strain, E. coli 1952 on nutrient broth, which was isolated from food source by using new logistic model equation (Fujikawa et al., 2004). Predictive
Table 2. Evaluation of primary models against experimental data of chicken breasts

\begin{tabular}{clcccc}
\hline \hline \multirow{2}{*}{$\begin{array}{c}\text { Tem- } \\
\text { perature }\end{array}$} & $\begin{array}{c}\text { Micro- } \\
\text { organism }\end{array}$ & \multicolumn{4}{c}{ Statistical analysis } \\
\cline { 3 - 6 } & $R M S E^{1)}$ & $B_{f}{ }^{2)}$ & $A_{f}{ }^{3)}$ & $R^{24)}$ \\
\hline \multirow{2}{*}{$5{ }^{\circ} \mathrm{C}$} & TVC $^{5)}$ & 0.15 & 0.998 & 1.013 & 0.97 \\
& EC $^{6)}$ & 0.09 & 1.022 & 1.023 & 0.95 \\
\hline \multirow{2}{*}{$15^{\circ} \mathrm{C}$} & TVC & 0.09 & 1.022 & 1.023 & 0.95 \\
& EC & 0.11 & 1.001 & 1.010 & 0.98 \\
\hline \multirow{2}{*}{$25^{\circ} \mathrm{C}$} & $\mathrm{TVC}$ & 0.11 & 1.001 & 1.010 & 0.98 \\
& EC & 0.05 & 1.010 & 1.017 & 0.97 \\
\hline
\end{tabular}

${ }^{1)}$ Root mean square error, ${ }^{2}$ bias factors, ${ }^{3)}$ accuracy factors, ${ }^{4)}$ correlation coefficient, ${ }^{5)}$ total viable cells, ${ }^{6}$ Escherichia coli.

growth parameters based on broth condition estimate much faster growth rate than those in real foods. Also, the maximum counts of bacteria differ from the surface of meat. Therefore, it is more reliable to develop growth models in real foods (Liu et al., 2006).

To describe the effects of temperature on growth of TVC and EC, the polynomial model was used as a secondary model for SGR and LT (Table 3). As storage temperature went up, SGR of TVC and EC increased, respectively, and inversely LT were shortened (Fig. 2(A) and 2(B)). Other scientific studies showed that the most significant factor for microorganism growth is storage temperature (Hong et al., 2005; Gospavic et al., 2008). During distribution processing, the temperature changes might affect the growth of microorganisms and spoilage of chicken breast mainly.

\section{Evaluation of predictive models}

To evaluate the developed predictive models, the indices used for comparisons of predicted and observed data were $B_{f}, A_{f}, R M S E$, and $R^{2}$. Tables 2 and 3 indicate how well the primary and secondary models described the growth data used in model development, respectively

Table 1. Growth parameters of microorganisms on chicken breasts

\begin{tabular}{cccccc}
\hline \hline \multirow{2}{*}{ Microorganism } & \multirow{2}{*}{ Temperature $\left({ }^{\circ} \mathrm{C}\right)$} & \multicolumn{4}{c}{ Growth parameters } \\
\cline { 3 - 6 } & & $y_{0}{ }^{1)}$ & $y_{\max }{ }^{2)}$ & SGR $^{3)}$ & LT $^{4)}$ \\
\hline & 5 & $4.23 \pm 0.15^{\mathrm{A} 7)}$ & $6.81 \pm 0.10^{\mathrm{B}}$ & $0.12 \pm 0.03^{\mathrm{C}}$ & $31.04 \pm 8.18^{\mathrm{A}}$ \\
TVC $^{5)}$ & 15 & $4.36 \pm 0.05^{\mathrm{A}}$ & $7.26 \pm 0.03^{\mathrm{AB}}$ & $0.25 \pm 0.03^{\mathrm{B}}$ & $10.73 \pm 1.53^{\mathrm{B}}$ \\
& 25 & $4.40 \pm 0.09^{\mathrm{A}}$ & $7.86 \pm 0.06^{\mathrm{A}}$ & $0.50 \pm 0.05^{\mathrm{A}}$ & $10.21 \pm 1.08^{\mathrm{B}}$ \\
\hline & 5 & $1.00 \pm 0.11^{\mathrm{a}}$ & $5.16 \pm 0.12^{\mathrm{b}}$ & $0.09 \pm 0.01^{\mathrm{c}}$ & $49.24 \pm 6.80^{\mathrm{a}}$ \\
$\mathrm{EC}^{6)}$ & 15 & $0.95 \pm 0.12^{\mathrm{a}}$ & $6.73 \pm 0.12^{\mathrm{a}}$ & $0.10 \pm 0.01^{\mathrm{b}}$ & $4.82 \pm 5.89^{\mathrm{b}}$ \\
& 25 & $0.88 \pm 0.20^{\mathrm{ab}}$ & $6.71 \pm 0.11^{\mathrm{a}}$ & $0.24 \pm 0.02^{\mathrm{a}}$ & $0.47 \pm 2.84^{\mathrm{c}}$ \\
\hline
\end{tabular}

${ }^{1)}$ The initial cell count (Log CFU/g), ${ }^{2}$ the maximum cell count $(\log \mathrm{CFU} / \mathrm{g}),{ }^{3)}$ the maximum specific growth rate (Log CFU/g/h), ${ }^{4)}$ the lag time (h), ${ }^{5)}$ total viable cell, ${ }^{6}$ Escherichia coli, ${ }^{7)}$ mean \pm standard error.

${ }^{A-C}$ Means in the same column of TVC with different superscripts differ significantly $(p<0.05)$.

${ }^{\mathrm{a}-\mathrm{c}}$ Means in the same column of EC with different superscripts differ significantly $(p<0.05)$. 
Table 3. Developments and evaluation of secondary models of microorganisms on chicken breasts

\begin{tabular}{clrrrr}
\hline \hline \multirow{2}{*}{ Microorganism } & \multicolumn{4}{c}{ Polynomial model equation } \\
\cline { 2 - 6 } & Ln $\left(\mathrm{SGR}\right.$ or LT) $=a+b \times \mathrm{T}+c \times \mathrm{T}^{2}$ & $R M S E^{1)}$ & $B_{f}{ }^{2)}$ & $A_{f}{ }^{3)}$ & $R^{24)}$ \\
\hline \multirow{2}{*}{$\mathrm{TVC}^{5)}$} & $\operatorname{Ln}(\mathrm{SGR})=-3.4397+0.0823 \times \mathrm{T}+0.00126 \times \mathrm{T}^{2}$ & 0.08 & 1.012 & 1.014 & 0.93 \\
& $\operatorname{Ln}(\mathrm{LT})=4.7038-0.231 \times \mathrm{T}+0.00525 \times \mathrm{T}^{2}$ & 0.08 & 0.999 & 1.015 & 0.95 \\
\hline \multirow{2}{*}{$\mathrm{EC}^{6)}$} & $\operatorname{Ln}(\mathrm{SGR})=-3.1712+0.0373 \times \mathrm{T}+0.00192 \times \mathrm{T}^{2}$ & 0.02 & 1.010 & 1.003 & 0.94 \\
& $\operatorname{Ln}(\mathrm{LT})=. .3 .7425-0.0462 \times \mathrm{T}-0.00123 \times \mathrm{T}^{2}$ & 0.02 & 0.994 & 1.008 & 0.97 \\
\hline
\end{tabular}

${ }^{1)}$ Root mean square error, ${ }^{2)}$ bias factors, ${ }^{3)}$ accuracy factors, ${ }^{4)}$ correlation coefficient, ${ }^{5)}$ total viable cells, ${ }^{6}$ Escherichia coli.

under isothermal conditions at different temperatures. In each case, predictive models produced high values for $R^{2}$ (the ideal value, 1.0) and small values for the RMSE (the ideal value, 0 ). Also $B_{f}$ and $A_{f}$ were used to compare the experimental data with predictive data (Baranyi et al., 1996). It was reported that values of $B_{f}$ in the range of 0.9-1.05 can describe well, in the range of $0.7-0.9$ or 1.15 considered acceptable, and $<0.7$ or $>1.5$ considered unacceptable (Ross, 1996). Based on the indices (Tables 2 and 3 ), the Baranyi and polynomial model equation which were used to develop models can present the growth of TVC and EC on chicken breasts well. In other words, developed primary models had a good fitness between predicted and observed data.

\section{Acknowledgment}

This study was supported by Technology Development Program for Agriculture and Forestry (Project: 10800202-1-CG000), Ministry for Food, Agriculture, Forestry and Fisheries, Republic of Korea.

\section{References}

1. BAM (2003) Bacteriological Analytical Manual Online. Available from http://www.cfsan.fda.gov/ ebam. Accessed 1 March 2009.

2. Baranyi, J. and Roberts, T. A. (1994) A dynamic approach to predicting bacterial growth in foods. Int. J. Food Microbiol. 23, 277-294.

3. Baranyi, J., Ross, T., Roberts, A., and McMeekin, T. A. (1996) Effects of parameterization on the performance of empirical models used in 'predictive microbiology'. Food Microbiol. 13, 83-91.

4. Center for Disease Control and Prevention (2005) Salmonellosis: Available from http://www.cdc.gov/nczved/dfbmd/ disease_listing/salmonellosis_gi.html. Accessed 1 March 2009.

5. Cha, S. K., Seo, M. Y., Kim, Y. S., Kim, M. H., and Kim, Y, J. (2004) The incidence of microorganisms during the slaughtering process of chicken. Korean J. Food Sci. Ani.
Resour. 24, 335-341.

6. Fujikawa, H., Kai, A., and Morozumi, S. (2004) A new logistic model for Escherichia coli growth at constant and dynamic temperature. Food Microbiol. 21, 501-509.

7. Gill, C. O., Moza, L. F., Badoni, M., and Barbut, S. (2006) The effects on the microbiological condition of product of carcass dressing, cooling, and portioning processes at a poultry packing plant. Int. J. Food Microbiol. 110, 187-193.

8. Gospavic, R., Kreyenschmidt, J., Bruckner, S., Popov, V., and Haque, N. (2008) Mathematical modeling for predicting the growth of Pseudomonas spp. in poultry under variable temperature conditions. Int. J. Food Microbiol. 128, 290297.

9. Hong, C., Sim, W., Chun, S., Kim, Y., Oh, D., Ha, S., Choi, W., and Bahk, G. (2005) Predictive growth model for native isolated Listeria monocytogenes on raw pork as a function of temperature and time. Korean J. Food Sci. Technol. 37, 850855.

10. Juneja, V. K., Melendres, M. V., Huang, L., Gumudavelli, V., Subbiah, J, and Thippareddi. H. (2007) Modeling the effect of temperature on growth of Salmonella in Chicken. Food Microbiol. 24, 328-335.

11. Liu, F., Guo, Y., and Li, Y. (2006) Interactions of microorganisms during natural spoilage of pork at $5^{\circ} \mathrm{C}$. J. Food Eng. 72, 24-29.

12. Michael P. D. and Beuchat L. R. (2007) Food microbiology: Fundamentals and Frontiers. 3rd ed, ASM Press, Washington, DC, pp. 971-985.

13. MicroFit (1995) MicroFit version 1.0. Institute of Food Research, Norwich, UK.

14. Ministry for Food Agriculture, Forestry, and Fisheries. (1999) The application manual for HACCP (MIFAFF, Notification No. 1999-29).

15. Oh Y. and Lee, S. (2001) Hygienic quality of beef and distribution of pathogens during cut-meat processing. J. Fd. Hyg. Safety 16, 96-102.

16. Ross, T. (1996) Indices for performance evaluation of predictive models in food microbiology. J. Appl. Bacteriol. 81, 501-508.

17. SAS (1999) SAS/STAT Software. Release 8.1, SAS Institute Inc., Cary, NC, USA.

18. Seo, K., Heo, S., Lee, A., Chung, D. H., Kim, M., Lee, K., Kim, K., Bahk, G., Bae, D., Kim, K., Kim, C., and Ha, S. (2007) Development of predictive mathematical model for the growth kinetics of Staphylococcus aureus by response 
surface model. J. Microbiol. Biotechnol. 17, 1437-1444.

19. Thomas, J. M. and Mattthews, K. R. (2005) Food microbiology: an introduction. ASM Press, Washington, DC, pp. 247250.

20. Zurera-Cosano, G., Garcia-Gimeno, R. M., Rodiguez-Perez, R., and Hervas-Martinez, C. (2006) Performance of response surface model for prediction of Leuconostoc mesenteroides growth parameters under different experimental conditions. Food Control 17, 429-438.

(Received 2009.7.30/Revised 1st 2010.1.13, 2nd 2010.2.16/Accepted 2010.2.17) 